\title{
Futures hedging with basis risk and expectation dependence
}

\author{
Udo Broll · Peter Welzel · Kit Pong Wong
}

\begin{abstract}
This paper examines the behavior of the competitive firm under price uncertainty. The firm has access to a futures market for hedging purposes. Basis risk exists because the random spot and futures prices are not identical at the time when the futures contracts mature. We show that the firm optimally produces less in the presence than in the absence of the basis risk. We show further that the concept of expectation dependence that describes how the basis risk is correlated with either the random spot price or the random futures price plays a pivotal role in determining the firm's optimal futures position. Specifically, an under-hedge is optimal if either the random spot price or the random futures price is negatively expectation dependent on the basis risk. On the other hand, an over-hedge is optimal if the random futures price is positively expectation dependent on the basis risk. The firm's optimal futures position becomes indeterminate if the random spot price is positively expectation dependent on the basis risk.
\end{abstract}

Keywords Basis risk $\cdot$ Futures hedging $\cdot$ Production $\cdot$ Prudence

JEL Classification D21 - D81 · G13

We would like to thank Luca Stanca (Co-Editor) and two anonymous referees for their helpful comments and suggestions. The usual disclaimer applies.

Udo Broll (Corresponding author)

Department of Business and Economics, School of International Studies (ZIS), Technische Universität Dresden, 01062 Dresden, Germany

e-mail: udo.broll@tu-dresden.de

Peter Welzel

Department of Business and Economics, Universität Augsburg, 86135 Augsburg, Germany

e-mail: peter.welzel@wiwi.uni-augsburg.de

Kit Pong Wong

School of Economics and Finance, University of Hong Kong, Pokfulam Road, Hong Kong, China e-mail: kpwong@econ.hku.hk 


\section{Introduction}

The seminal work of Sandmo (1971) has inspired a large body of research on the theory of the competitive firm under price uncertainty. One important strand of this literature examines the behavior of the firm when a futures market exists for hedging purposes, from which two celebrated theorems emanate (see, e.g., Adam-Müller, 1997; Broll, 1992; Broll and Zilcha, 1992; Danthine, 1978; Feder et al., 1980; Holthausen, 1979; to name just a few). First, the separation theorem states that the firm's optimal output level depends neither on the risk attitude of the firm, nor on the incidence of the price uncertainty. Second, the full-hedging theorem asserts that the firm should fully hedge against its exposure to the price risk if the futures market is unbiased. ${ }^{1}$

The purpose of this paper is to examine the robustness of the separation and full-hedging theorems when basis risk is embedded in the futures contracts, i.e., the random futures price does not converge to the random spot price at the time when the futures contracts mature. There are various reasons why basis risk exists. First, the timing of the spot position may not synchronize the settlement date of the futures position. Second, the underlying asset of the spot position may not be identical to that of the futures position. Third, nearly all commodity futures contracts have multiple delivery specifications that allow sellers to deliver any of several grades of the underlying commodity and at any of several locations. On the delivery date, the futures price as such converges to the spot price of the cheapestto-deliver grade and not to that of the par-delivery grade of the commodity (Adam-Müller and Wong, 2003; Kamara and Siegel, 1987; Lien, 1988, 1991; Lien and Wong, 2002; Wong, 2014).

We show that the separation theorem fails to hold when basis risk prevails. To limit its exposure to the basis risk, the firm has incentives to use operational hedging by cutting down its optimal output level. The firm as such produces less in the presence than in the

\footnotetext{
${ }^{1}$ The full-hedging theorem is analogous to a well-known result in the insurance literature that a risk-averse individual fully insures at an actuarially fair price (Mossin, 1968).
} 
absence of the basis risk, thereby invalidating the separation theorem. The full-hedging theorem, however, holds if the random futures price is conditionally independent of the basis risk. Since the basis risk is not hedgeable by trading the unbiased futures contracts further, a full-hedge is indeed optimal in this special case.

In the general case that the basis risk is correlated with either the random spot price or the random futures price, we show that the concept of expectation dependence (Wright, 1987) plays a pivotal role in determining the firm's optimal futures position. ${ }^{2}$ Specifically, we show that an under-hedge is optimal if either the random spot price or the random futures price is negatively expectation dependent on the basis risk. On the other hand, an over-hedge is optimal if the random futures price is positively expectation dependent on the basis risk. The firm's optimal futures position becomes indeterminate if the random spot price is positively expectation dependent on the basis risk.

The rest of this paper is organized as follows. Section 2 delineates the model of the competitive firm under price uncertainty. The firm has access to a futures market for hedging purposes. Basis risk exists because the random spot and futures prices are not identical at the time when the futures contracts mature. Section 3 characterizes the firm's optimal production decision. Section 4 examines the firm's optimal hedging decision. The final section concludes.

\section{The model}

Consider the competitive firm under output price uncertainty à la Sandmo (1971). There is one period with two dates, 0 and 1 . To begin, the firm produces a single commodity according to a deterministic cost function, $C(Q)$, where $Q \geq 0$ is the output level chosen by the firm at date 0 , and $C(Q)$ is compounded to date 1 . We assume that the cost function,

\footnotetext{
${ }^{2}$ See Broll and Wong (2014), Hong et al. (2011), Li (2011), and Wong (2012, 2013) for other applications of expectation dependence.
} 
$C(Q)$, satisfies that $C(0)=C^{\prime}(0)=0, C^{\prime}(Q)>0$ and $C^{\prime \prime}(Q)>0$ for all $Q>0$, and $\lim _{Q \rightarrow \infty} C^{\prime}(Q)=\infty .{ }^{3}$ The firm sells its entire output at the then prevailing per-unit price, $\tilde{P}$, at date 1 . The firm regards the spot price, $\tilde{P}$, as a random variable that is distributed according to a known cumulative distribution function $(\mathrm{CDF}), \Phi(P)$, over support $[\underline{P}, \bar{P}]$, where $0<\underline{P}<\bar{P}<\infty .^{4}$

Although there are no hedging instruments directly related to the random spot price, $\tilde{P}$, the firm can cross-hedge its risk exposure to $\tilde{P}$ by trading infinitely divisible futures contracts on a related commodity at date 0 . Specifically, each futures contract calls for delivery of one unit of the related commodity at date 1 . The futures price at date 0 is $F_{0}$, which is determined by the risk-neutral measure. The firm regards the futures price at date $1, \tilde{F}$, as a random variable that is distributed according to a known $\operatorname{CDF}, \Psi(F)$, over support $[\underline{F}, \bar{F}]$, where $0<\underline{F}<F_{0}<\bar{F}<\infty$. We define the basis risk embedded in the futures contracts by $\tilde{Z}=\tilde{P}-\tilde{F}$. Throughout the paper, we restrict our attention to the case that the basis risk, $\tilde{Z}$, has a mean of zero.

The firm's random profit at date 1 is given by

$$
\tilde{\Pi}=\tilde{P} Q+\left(F_{0}-\tilde{F}\right) H-C(Q)
$$

where $H$ is the number of the commodity futures contracts sold (purchased if negative) by the firm at date 0 . We say that the futures position, $H$, is an under-hedge, a fullhedge, or an over-hedge, depending on whether $H$ is smaller than, equal to, or greater than the output level, $Q$, respectively. The firm possesses a von Neumann-Morgenstern utility function, $U(\Pi)$, defined over its profit at date 1 , $\Pi$. The firm is risk averse so that $U^{\prime}(\Pi)>0$ and $U^{\prime \prime}(\Pi)<0$ for all $\Pi \in \Re$. The utility function satisfies the Inada condition in that $\lim _{\Pi \rightarrow \infty} U^{\prime}(\Pi)=0$.

The firm's ex-ante decision problem is to choose an output level, $Q \geq 0$, and a futures

\footnotetext{
${ }^{3}$ The strict convexity of $C(Q)$ reflects the fact that the firm's production technology exhibits decreasing returns to scale.

${ }^{4}$ Throughout the paper, random variables have a tilde $(\sim)$ while their realizations do not.
} 
position, $H$, at date 0 so as to maximize the expected utility of its profit at date 1 :

$$
\max _{Q \geq 0, H} \mathrm{E}[U(\tilde{\Pi})]
$$

where $\mathrm{E}(\cdot)$ is the expectation operator with respect to the joint $\mathrm{CDF}$ of $\tilde{P}$ and $\tilde{F}$, and $\tilde{\Pi}$ is given by Eq. (1). The first-order conditions for program (2) are given by

$$
\mathrm{E}\left\{U^{\prime}\left(\tilde{\Pi}^{*}\right)\left[\tilde{P}-C^{\prime}\left(Q^{*}\right)\right]\right\}=0,
$$

and

$$
\mathrm{E}\left[U^{\prime}\left(\tilde{\Pi}^{*}\right)\left(F_{0}-\tilde{F}\right)\right]=0,
$$

where an asterisk $\left(^{*}\right)$ signifies an optimal level. The second-order conditions for program (2) are satisfied given risk aversion and the strict convexity of the cost function.

\section{Optimal production decision}

In this section, we examine the firm's optimal production decision. As a benchmark, we consider first that the basis risk is absent, i.e., $\tilde{Z} \equiv 0$, so that $\tilde{P} \equiv \tilde{F}$. Substituting Eq. (4) with $\tilde{P} \equiv \tilde{F}$ into Eq. (3) yields the optimal output level, $Q^{\circ}$, that solves $C^{\prime}\left(Q^{\circ}\right)=F_{0}$. Hence, in the absence of the basis risk, the separation theorem holds in that $Q^{\circ}$ depends neither on the risk attitude of the firm nor on the underlying output price uncertainty.

We now resume the original case that $\tilde{P}$ is not identical to $\tilde{F}$. To compare $Q^{\circ}$ with $Q^{*}$, we proceed in two steps. First, we derive the optimal futures position, $H(Q)$, for a given output level, $Q$, which solves the following first-order condition:

$$
\mathrm{E}\left\{U^{\prime}[\tilde{\Pi}(Q)]\left(F_{0}-\tilde{F}\right)\right\}=0,
$$

where $\tilde{\Pi}(Q)=\tilde{P} Q+\left(F_{0}-\tilde{F}\right) H(Q)-C(Q)$. Second, taking the optimal futures position, $H(Q)$, that solves Eq. (5) as given, we differentiate the objective function of program (2) with respect to $Q$, and evaluate the resulting derivative at $Q=Q^{\circ}$ to yield

$$
\left.\frac{\partial \mathrm{E}[U(\tilde{\Pi})]}{\partial Q}\right|_{Q=Q^{\circ}, H=H\left(Q^{\circ}\right)}=\mathrm{E}\left\{U^{\prime}\left[\tilde{\Pi}\left(Q^{\circ}\right)\right]\left(\tilde{P}-F_{0}\right)\right\},
$$


since $C^{\prime}\left(Q^{\circ}\right)=F_{0}$. If the right-hand side of Eq. (6) is negative (positive), it follows from Eq. (3) and the second-order conditions for program (2) that $Q^{*}<(>) Q^{\circ}$.

Using the covariance operator, $\operatorname{Cov}(\cdot, \cdot)$, with respect to the joint $\operatorname{CDF}$ of $\tilde{P}$ and $\tilde{F}$, we can write Eq. (5) with $Q=Q^{\circ}$ as $^{5}$

$$
\mathrm{E}\left\{U^{\prime}\left[\tilde{\Pi}\left(Q^{\circ}\right)\right]\right\}\left[F_{0}-\mathrm{E}(\tilde{F})\right]-\operatorname{Cov}\left\{U^{\prime}\left[\tilde{\Pi}\left(Q^{\circ}\right)\right], \tilde{F}\right\}=0,
$$

and Eq. (6) as

$$
\left.\frac{\partial \mathrm{E}[U(\tilde{\Pi})]}{\partial Q}\right|_{Q=Q^{\circ}, H=H\left(Q^{\circ}\right)}=\mathrm{E}\left\{U^{\prime}\left[\tilde{\Pi}\left(Q^{\circ}\right)\right]\right\}\left[\mathrm{E}(\tilde{P})-F_{0}\right]+\operatorname{Cov}\left\{U^{\prime}\left[\tilde{\Pi}\left(Q^{\circ}\right)\right], \tilde{P}\right\} .
$$

Since $\tilde{\Pi}\left(Q^{\circ}\right)=\tilde{P} Q^{\circ}+\left(F_{0}-\tilde{F}\right) H\left(Q^{\circ}\right)-C\left(Q^{\circ}\right)$, we have

$$
\begin{gathered}
\operatorname{Cov}\left\{U^{\prime}\left[\tilde{\Pi}\left(Q^{\circ}\right)\right], \tilde{\Pi}\left(Q^{\circ}\right)\right\}=\operatorname{Cov}\left\{U^{\prime}\left[\tilde{\Pi}\left(Q^{\circ}\right)\right], \tilde{P}\right\} Q^{\circ}-\operatorname{Cov}\left\{U^{\prime}\left[\tilde{\Pi}\left(Q^{\circ}\right)\right], \tilde{F}\right\} H\left(Q^{\circ}\right) \\
=\operatorname{Cov}\left\{U^{\prime}\left[\tilde{\Pi}\left(Q^{\circ}\right)\right], \tilde{P}\right\} Q^{\circ}+\mathrm{E}\left\{U^{\prime}\left[\tilde{\Pi}\left(Q^{\circ}\right)\right]\right\}\left[\mathrm{E}(\tilde{F})-F_{0}\right] H\left(Q^{\circ}\right)<0,
\end{gathered}
$$

where the second equality follows from Eq. (7) and the inequality follows from $U^{\prime \prime}(\Pi)<0$. Eq. (9) implies that the right-hand side of Eq. (8) is negative if $\mathrm{E}(\tilde{P}) \leq F_{0} \leq \mathrm{E}(\tilde{F})$. Since $\mathrm{E}(\tilde{Z})=0$, we have $\mathrm{E}(\tilde{P})=\mathrm{E}(\tilde{F})$.

Proposition 1 The competitive firm optimally produces less when the zero-mean basis risk, $\tilde{Z}$, is embedded in the unbiased commodity futures contracts than when it is not, i.e., $Q^{*}<Q^{\circ}$, if the futures contracts are unbiased in that $F_{0}=\mathrm{E}(\tilde{F})$.

To see the intuition for Proposition 1, we can write Eq. (1) as

$$
\tilde{\Pi}=F_{0} Q+\tilde{Z} Q+\left(\tilde{F}-F_{0}\right)(Q-H)-C(Q) .
$$

It is evident from Eq. (10) that the firm can limit its exposure to the zero-mean basis risk, $\tilde{Z}$, by reducing its output level. The firm as such uses operational hedging via setting $Q^{*}<Q^{\circ}$. This result holds irrespective of how the basis risk, $\tilde{Z}$, is correlated with either the random spot price, $\tilde{P}$, or the random futures price, $\tilde{F}$.

\footnotetext{
${ }^{5}$ For any two random variables, $\tilde{X}$ and $\tilde{Y}$, we have $\operatorname{Cov}(\tilde{X}, \tilde{Y})=\mathrm{E}(\tilde{X} \tilde{Y})-\mathrm{E}(\tilde{X}) \mathrm{E}(\tilde{Y})$.
} 


\section{Optimal hedging decisions}

In this section, we examine the firm's optimal hedging decision. To this end, we differentiate $\mathrm{E}[U(\tilde{\Pi})]$ with respect to $H$, and evaluate the resulting derivative at $Q=Q^{*}$ and $H=Q^{*}$ to obtain

$$
\left.\frac{\partial \mathrm{E}[U(\tilde{\Pi})]}{\partial H}\right|_{Q=Q^{*}, H=Q^{*}}=\mathrm{E}\left[U^{\prime}\left(\Pi^{*}+\tilde{Z} Q^{*}\right)\right]\left[F_{0}-\mathrm{E}(\tilde{F})\right]-\operatorname{Cov}\left[U^{\prime}\left(\Pi^{*}+\tilde{Z} Q^{*}\right), \tilde{F}\right]
$$

where $\Pi^{*}=\mathrm{E}(\tilde{P}) Q^{*}-C\left(Q^{*}\right)$. If the right-hand side of Eq. (11) is negative (positive), it follows from Eq. (4) and the second-order conditions for program (2) that $H^{*}<(>) Q^{*}$.

As a benchmark, we suppose that the basis risk is absent, i.e., $\tilde{Z} \equiv 0$, so that $Q^{*}=Q^{\circ}$. If $H=Q^{\circ}$, the firm's profit at date 1 becomes $F_{0} Q^{\circ}-C\left(Q^{\circ}\right)$, which is non-stochastic. Hence, we have

$$
\left.\frac{\partial \mathrm{E}[U(\tilde{\Pi})]}{\partial H}\right|_{Q=Q^{\circ}, H=Q^{\circ}}=\mathrm{E}\left\{U^{\prime}\left[F_{0} Q^{\circ}-C\left(Q^{\circ}\right)\right]\right\}\left[F_{0}-\mathrm{E}(\tilde{F})\right] .
$$

If $F_{0}=\mathrm{E}(\tilde{F})$, the right-hand side of Eq. (12) vanishes so that a full-hedge is optimal, which is simply the celebrated full-hedging theorem. If $F_{0}<(>) \mathrm{E}(\tilde{F})$, the right-hand side of Eq. (12) is negative (positive) so that an under-hedge (over-hedge) is optimal. In this case, the firm is induced to buy (sell) the futures contracts for speculative purposes, thereby rendering the firm to deviate from a full-hedge by adopting an under-hedge (over-hedge).

We now resume the original case that the random spot price, $\tilde{P}$, is not identical to the random futures price, $\tilde{F}$. Consider first that $\tilde{F}$ is conditionally independent of the basis risk, $\tilde{Z} .{ }^{6}$ According to Ingersoll (1987), we have $\operatorname{Cov}[f(\tilde{Z}), \tilde{F}]=0$ for all functions, $f(\cdot){ }^{7}$ Hence, the second term on the right-hand side of Eq. (11) vanishes. In this case, we have $H^{*}$ is smaller than, equal to, or greater than $Q^{*}$, if $F_{0}$ is smaller than, equal to, or greater than $\mathrm{E}(\tilde{F})$, respectively. Consider now that $\tilde{P}$ is conditionally independent of $\tilde{Z}$. According

\footnotetext{
${ }^{6}$ Lence (1995) uses the concept of conditional independence to derive a necessary and sufficient condition for a constant optimal hedge ratio.

${ }^{7}$ Ingersoll (1987) shows that $\tilde{X}$ is conditionally independent of $\tilde{Y}$ if $\operatorname{Cov}[f(\tilde{Y}), \tilde{X}]=0$ for all functions, $f(\cdot)$. He further shows that $\tilde{X}$ and $\tilde{Y}$ are independent if $\operatorname{Cov}[f(\tilde{X}), g(\tilde{Y})]=0$ for all functions, $f(\cdot)$ and $g(\cdot)$. Hence, the concept of conditional independence is weaker than that of independence.
} 
to Ingersoll (1987), we have $\operatorname{Cov}[f(\tilde{Z}), \tilde{P}]=0$ for all functions, $f(\cdot)$. The second term on the right-hand side of Eq. (11) becomes $\operatorname{Cov}\left[U^{\prime}\left(\Pi^{*}+\tilde{Z} Q^{*}\right), \tilde{Z}\right]<0$ since $\tilde{F}=\tilde{P}-\tilde{Z}$ and $U^{\prime \prime}(\Pi)<0$. Hence, in this case, we have $H^{*}<Q^{*}$ if $F_{0}$ does not exceed $\mathrm{E}(\tilde{F})$.

Proposition 2 Given that the random futures price, $\tilde{F}$, is conditionally independent of the zero-mean basis risk, $\tilde{Z}$, the competitive firm optimally opts for an under-hedge, a fullhedge, or an over-hedger, depending on whether $F_{0}$ is smaller than, equal to, or greater than $\mathrm{E}(\tilde{F})$, respectively. Given that the random spot price, $\tilde{P}$, is conditionally independent of $\tilde{Z}$, the firm optimally opts for an under-hedge if $F_{0} \leq \mathrm{E}(\tilde{F})$.

The intuition for Proposition 2 is as follows. Suppose that the firm adopts a fullhedge, i.e., $H^{*}=Q^{*}$. In this case, the firm's profit at date 1 becomes $\Pi^{*}+\tilde{Z} Q^{*}$, which remains stochastic because of the presence of the basis risk, $\tilde{Z}$. If the random futures price, $\tilde{F}$, is conditionally independent of $\tilde{Z}$, the basis risk is not hedgeable by trading the futures contracts further so that the full-hedge is optimal for hedging purposes. Given that $F_{0}<(>) \mathrm{E}(\tilde{F})$, there is a speculative motive that makes an under-hedge (over-hedge) optimal. On the other hand, if the random spot price, $\tilde{P}$, is conditionally independent of $\tilde{Z}$, the firm can limit its exposure to the basis risk by reducing its futures position from the full-hedge, thereby rendering the optimality of an under-hedge, i.e., $H^{*}<Q^{*}$, which is reinforced (counteracted) by the speculative motive given that $F_{0}<(>) \mathrm{E}(\tilde{F})$.

We now turn to the general case that the basis risk, $\tilde{Z}$, is correlated with either the random futures price, $\tilde{F}$, or the random spot price, $\tilde{P}$. Consider first that $\tilde{F}$ is negatively (positively) expectation dependent on the basis risk, $\tilde{Z}$, in the sense of Wright (1987). According to Wright (1987), we have $\operatorname{Cov}[f(\tilde{Z}), \tilde{F}]<(>) 0$ for all increasing functions, $f(\cdot)$. Hence, the second term on the right-hand side of Eq. (11) is negative (positive). In this case, we have $H^{*}$ is smaller (greater) than $Q^{*}$, if $F_{0}$ is no greater (smaller) than $\mathrm{E}(\tilde{F})$. Consider now that $\tilde{P}$ is negatively (positively) expectation dependent on $\tilde{Z}$. According to Wright $(1987)$, we have $\operatorname{Cov}[f(\tilde{Z}), \tilde{P}]<(>) 0$ for all increasing functions, $f(\cdot)$. The 
sign of the second term on the right-hand side of Eq. (11) is negative (ambiguous) since $\operatorname{Cov}\left[U^{\prime}\left(\Pi^{*}+\tilde{Z} Q^{*}\right), \tilde{Z}\right]<0$. Hence, in this case, we have $H^{*}<Q^{*}$ if $F_{0}$ does not exceed $\mathrm{E}(\tilde{F})$ and $\tilde{P}$ is negatively expectation dependent on $\tilde{Z}$.

Proposition 3 Given that the random futures price, $\tilde{F}$, is negatively (positively) expectation dependent on the zero-mean basis risk, $\tilde{Z}$, the competitive firm optimally opts for an underhedge (over-hedger) if $F_{0}$ is no greater (smaller) than $\mathrm{E}(\tilde{F})$. Given that the random spot price, $\tilde{P}$, is negatively expectation dependent on $\tilde{Z}$, the firm optimally opts for an underhedge if $F_{0} \leq \mathrm{E}(\tilde{F})$.

To see the intuition for Proposition 3, we focus on the case that $F_{0}=\mathrm{E}(\tilde{F})$ so that the firm has no speculative motive. Given that covariances can be interpreted as marginal variances, Eq. (4) implies that the optimal futures position, $H^{*}$, is the one that minimizes the variance of the firm's marginal utility. Consider first the case that the random futures price, $\tilde{F}$, and the basis risk, $\tilde{Z}$, are negatively (positively) correlated in the sense of expectation dependence. In this case, a full-hedge, i.e., $H^{*}=Q^{*}$, that completely eliminates the risk from the random spot price, $\tilde{P}$, is suboptimal because the firm's profit at date $1, \Pi^{*}+\tilde{Z} Q^{*}$, remains stochastic. Given that $\tilde{F}$ and $\tilde{Z}$ are negatively (positively) correlated, the firm is induced to opt for a long (short) futures position to hedge against the basis risk, thereby rendering the optimality of an under-hedge (over-hedge).

Consider now the case that the random spot price, $\tilde{P}$ and the basis risk, $\tilde{Z}$, are negatively (positively) correlated in the sense of expectation dependence. Substituting $\tilde{F}=\tilde{P}-\tilde{Z}$ into Eq. (1) yields

$$
\tilde{\Pi}^{*}=\Pi^{*}+\tilde{Z} H^{*}+[\tilde{P}-\mathrm{E}(\tilde{P})]\left(Q^{*}-H^{*}\right) .
$$

As is evident from Eq. (13), the firm has the incentive to limit its exposure to the basis risk, $\tilde{Z}$, by reducing its futures position (see also Proposition 2). Given that $\tilde{P}$ and $\tilde{Z}$ are negatively (positively) correlated, the firm is induced to opt for a long (short) futures position to hedge against the basis risk. Combining these effects implies that the firm's 
optimal futures position is an under-hedge if $\tilde{P}$ is negatively expectation dependent on $\tilde{Z}$, and becomes indeterminate if $\tilde{P}$ is positively expectation dependent on $\tilde{Z}$.

\section{Conclusion}

This paper examines the behavior of the competitive firm under price uncertainty $\grave{a}$ la Sandmo (1971). The firm has access to a futures market for hedging purposes. Basis risk arises from the difference between the random spot and futures prices at the time when the futures contracts mature. We show that the separation theorem fails to hold when the basis risk prevails. To limit its exposure to the basis risk, the firm is induced to use operational hedging by reducing its optimal output level. The firm as such produces less in the presence than in the absence of the basis risk, thereby invalidating the separation theorem. The fullhedging theorem, however, holds if the random futures price is conditionally independent of the basis risk. Since the basis risk is not hedgeable by trading the unbiased futures contracts further, a full-hedge is indeed optimal in this special case.

In the general case that the basis risk is correlated with either the random spot price or the random futures price, we show that the concept of expectation dependence (Wright, 1987) plays a pivotal role in shaping the firm's optimal hedging decision. If either the random spot price or the random futures price is negatively expectation dependent on the basis risk, we show that the firm's optimal futures position is an under-hedge. If the random futures price is positively expectation dependent on the basis risk, the firm's optimal futures position is an over-hedge. Finally, the firm's optimal futures position becomes indeterminate if the random spot price is positively expectation dependent on the basis risk.

\section{References}

Adam-Müller AFA (1997) Export and hedging decisions under revenue and exchange rate 
risk: a note. European Economic Review 41:1421-1426

Adam-Müller AFA, Wong KP (2003) The impact of delivery risk on optimal production and futures hedging. European Finance Review 7:459-477

Broll U (1992) The effect of forward markets on multinational firms. Bulletin of Economic Research 44:233-240

Broll U, Wong KP (2014) Trade and cross hedging exchange rate risk. International Economics and Economic Policy (forthcoming)

Broll U, Zilcha I (1992) Exchange rate uncertainty, futures markets and the multinational firm. European Economic Review 36:815-826

Danthine J-P (1978) Information, futures prices, and stabilizing speculation. Journal of Economic Theory 17:79-98

Feder G, Just RE, Schmitz A (1980) Futures markets and the theory of the firm under price uncertainty. Quarterly Journal of Economics 94:317-328

Holthausen DM (1979) Hedging and the competitive firm under price uncertainty. American Economic Review 69:989-995

Hong SK, Lew KO, MacMinn R, Brockett P (2011) Mossin's Theorem given random initial wealth. Journal of Risk and Insurance 78:309-324

Ingersoll JE (1987) Theory of financial decision making. Totowa: Rowman and Littlefield

Kamara A, Siegel AF (1987) Optimal hedging in futures markets with multiple delivery specifications. Journal of Finance 42:1007-1021

Lence SH (1995) On the optimal hedge under unbiased futures prices. Economics Letters $47: 385-388$

Li J (2011) The demand for a risky asset in the presence of a background risk. Journal of Economic Theory 146:372-391 
Lien D (1988) Hedger response to multiple grades of delivery on futures markets. Journal of Futures Markets 8:687-702

Lien D (1991) Long hedgers and multiple delivery specifications on futures contracts. Journal of Futures Markets 11:557-565

Lien D, Wong KP (2002) Delivery risk and the hedging role of options. Journal of Futures Markets 22:339-354

Mossin J (1968) Aspects of rational insurance purchasing. Journal of Political Economy $76: 553-568$

Sandmo A (1971) On the theory of the competitive firm under price uncertainty. American Economic Review 61:65-73

Wong KP (2012) Production and hedging under state-dependent preferences. Journal of Futures Markets 32:945-963

Wong KP (2013) Cross hedging with currency forward contracts. Journal of Futures Markets 33:653-674

Wong KP (2014) Production and hedging in futures markets with multiple delivery specifications. Decisions in Economics and Finance 37:413-421

Wright R (1987) Expectation dependence of random variables, with an application in portfolio theory. Theory and Decision 22:111-124 